(2) Open Access Full Text Article

REVIEW

\title{
An evidence-based review of certolizumab pegol in the treatment of active psoriatic arthritis: place in therapy
}

This article was published in the following Dove Press journal:

Open Access Rheumatology: Research and Reviews

30 March 2016

Number of times this article has been viewed

\section{María Laura Acosta-Felquer Javier Rosa Enrique R Soriano \\ Rheumatology Unit, Internal Medical Services, and University Institute, Hospital Italiano de Buenos Aires, Buenos Aires, Argentina}

\begin{abstract}
Certolizumab pegol (CZP) is a pegylated humanized tumor necrosis factor- $\alpha$ inhibitor (TNFi) approved for the treatment of psoriatic arthritis (PsA) in Europe, the USA, and Latin American countries. CZP neutralizes TNF- $\alpha$ at its soluble and membrane portions. Due to the lack of Fc region, it does not induce complement or antibody-dependent cytotoxicity in vitro, unlike other TNFi. RAPID-PsA study, the only randomized clinical trial performed in PsA, is a Phase III clinical trial conducted in 409 PsA patients during 24 weeks. Patients were randomized to CZP (200 mg every 2 weeks or $400 \mathrm{mg}$ every 4 weeks) or placebo. Patients in CZP arms reported improvements in skin disease, joint involvement, dactylitis, enthesitis, and quality of life. Safety profile was similar to that reported for other TNF- $\alpha$ inhibitors in PsA patients. This article summarizes the pharmacology and reviews the efficacy and tolerability of this drug in PsA. CZP is the newest TNFi with proved efficacy in all manifestations of psoriasis disease, except for axial involvement where the evidence has been derived from response to axial spondyloarthritis.
\end{abstract}

Keywords: certolizumab pegol, tumor necrosis factor- $\alpha$ inhibitors, psoriatic arthritis, efficacy, safety

\section{Introduction}

Psoriatic arthritis (PsA) is a chronic inflammatory musculoskeletal disease associated with psoriasis (Ps). The prevalence of PsA in the general population has been found to vary among different countries and different studies, with a median of 180 cases per $10^{5}$ population. ${ }^{1,2}$ Between $6 \%$ and $42 \%$ of patients with Ps have PsA. ${ }^{3}$ PsA that was once thought as a benign rheumatic disease is nowadays considered a progressive disease, where a substantial number of patients can develop erosions and major structural damage. ${ }^{4-7}$ PsA has a negative impact on the quality of life, both physically and emotionally, compared with the general population and with Ps patients. Also, as described in patients with rheumatoid arthritis (RA), PsA patients have impaired functional capacity, and increased mortality rate, particularly from cardiovascular disease..$^{8-11}$

PsA is a complex and heterogeneous disease, since there are different facets in the phenotypic expression of the disease. The response to different treatments may vary according to axial or peripheral joint involvement, and also, extra-articular manifestations (skin, nails), enthesitis, and dactylitis. ${ }^{12}$ Another factor to keep in mind for assessing response to treatment is the presence of metabolic syndrome. Metabolic syndrome is associated with a lower probability of achieving minimal disease activity (MDA) in PsA patients on therapy with tumor necrosis factor inhibitors (TNFi). ${ }^{13}$ In a similar
Correspondence: Enrique R Soriano Rheumatology Unit, Internal Medical Services, and University Institute, Hospital Italiano de Buenos Aires, Juan D. Perón $4190(\mathrm{Cl}|8| \mathrm{ACH})$,

Buenos Aires, Argentina

Tel + 54 II 49590200 ext 5443

Fax +54 II 49590378

Email enrique.soriano@hospitalitaliano. org.ar (c) (1) (5) 2016 Acosta-Felquer et al. This work is published and licensed by Dove Medical Press Limited. The full terms of this license are available at https://www.dovepress.com/ cc) ${ }_{\mathrm{BY}} \mathrm{NC}$ terms.php and incorporate the Creative Commons Attribution - Non Commercial (unported, v3.0) License (httrp://creativecommons.org/licensses/by-nc/3.0/). By accessing the work you hereby accept the Terms. Non-commercial uses of the work are permitted without any further permission from Dove Medical Press Limited, provided the work is properly attributed. For permission for commercial use of this work, please see paragraphs 4.2 and 5 of our Terms (https://www.dovepress.com/terms.php). 
way, patients with PsA who are overweight and obese are less likely to achieve MDA, compared with normal-weight patients. ${ }^{14}$ In addition, patients treated with etanercept and adalimumab (ADA) showed significant improvement of the various components of the metabolic syndrome (waist circumference, triglycerides, high-density lipoprotein cholesterol, and glucose), as compared with the group treated with methotrexate (MTX). ${ }^{15}$ As seen in RA, new paradigms in the treatment of PsA have emerged in recent years and have gained great acceptance in the rheumatology community. ${ }^{16}$ These include early treatment, ${ }^{17}$ remission as a therapeutic goal, ${ }^{18}$ the assessment of joint and extra-articular involvement of this heterogeneous disease, ${ }^{19}$ and frequent measurement of disease activity in order to adjust the treatment according to the principles of Treat to Target. ${ }^{20}$

Treatment of PsA has changed dramatically in recent years, despite the limited knowledge about its etiology and pathogenesis and the relative paucity of randomized controlled clinical trials, due to the introduction of biologic agents, especially TNFi. Nonbiologic diseasemodifying antirheumatic drugs (DMARDs), such as MTX, sulfasalazine, and leflunomide, however, remain as the first-line therapy recommended by all clinical guidelines, even though evidence of their efficacy is scarce. ${ }^{16,21-23}$ This recommendation is based on rheumatologists' clinical experience and evidence from observational studies. ${ }^{24}$ There are five TNFi approved by the US Food and Drug Administration for use in PsA: infliximab (IFX), etanercept, ADA, golimumab, and most recently, certolizumab pegol (CZP). ${ }^{25-29} \mathrm{TNF}-\alpha$ is a proinflammatory cytokine that is found in soluble form or bounded to the membrane of macrophages and lymphocytes. Elevated levels of TNF- $\alpha$ have been found in the targeted tissues of patients with different chronic inflammatory diseases. This finding, together with data on the clinical efficacy of pharmacological blockade of this cytokine, has confirmed the essential role of TNF- $\alpha$ in the pathogenesis of conditions such as RA, spondyloarthropathies, PsA, and Crohn's disease. ${ }^{30}$ TNF- $\alpha$ plays a key role in the pathogenesis of Ps and PsA by inducing the production of other inflammatory cytokines such as interleukin (IL)-1, IL-6, IL-8, and several matrix metalloproteinases. Also, it causes joint damage by stimulating bone resorption and inhibiting bone formation. TNF- $\alpha$ also contributes to vascular proliferation, the relevant phenomenon in many inflammatory diseases. Treatments that block some of these cytokines have shown not only improvement on joint damage but also prevention of cardiovascular damage as well. ${ }^{31}$
All anti-TNF agents have shown comparable efficacy in the treatment of peripheral arthritis in PsA and there is also strong evidence that they improve skin involvement, dactylitis, and enthesitis. ${ }^{32,33}$ An important difference from RA is that biologic agents in PsA may be used as monotherapy, although data from some registers have shown increased survival of anti-TNF with the concomitant use of MTX. ${ }^{16}$ In this review, we describe the evidence for the use of CZP in the treatment of active PsA, with focus on its mechanism of action, efficacy, and safety.

\section{Certolizumab pegol}

There are two important regions of antibodies, the fragment antigen-binding (Fab) and the fragment crystallizable (Fc) regions (Figure 1). The Fab region contains complementaritydetermining regions, unique sequences of amino acids responsible for binding antigen. The Fc region is not antigen specific, but is necessary for other antibody functions such as complement fixation and cell lysis.

CZP is a novel TNFi formed by a humanized Fab fragment $(50 \mathrm{kDa})$ fused to a $40 \mathrm{kDa}$ polyethylene glycol (PEG) moiety (a nontoxic and nonimmunogenic polymer) (Figure 2). The lack of Fc region in CZP prevents activities such as complement fixation and antibody-mediated cytotoxicity. The attachment of the $40 \mathrm{kDa}$ PEG moiety to the Fab fragment markedly increases the half-life of CZP to a value comparable with that of a whole antibody product. ${ }^{30,31}$

\section{Mechanism of action}

CZP specifically recognizes and neutralizes human TNF, both the soluble and membrane-bound forms, in a dose-dependent

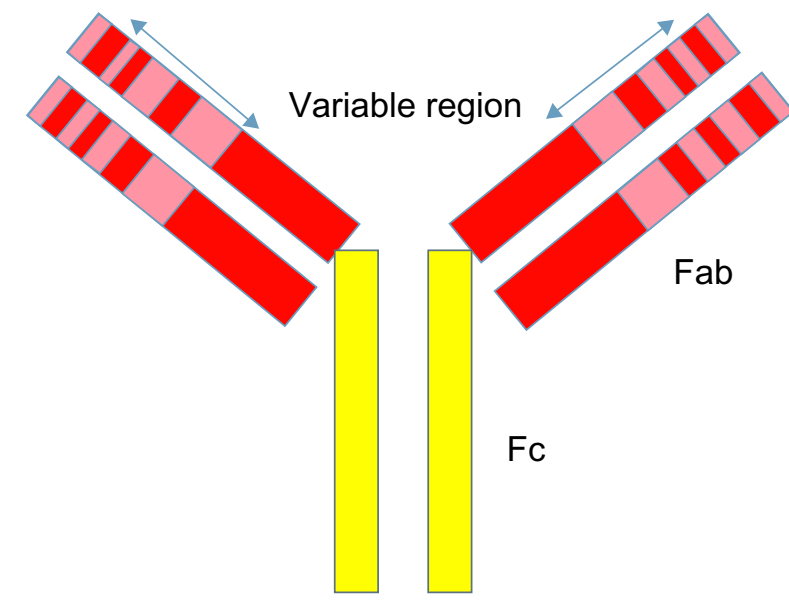

Figure I Antibody structure. Each chain is divided into regions or domains. Notes: The light chain has two domains and the heavy chain has four domains. The Fab region is responsible for the unique specificity of antibody molecules to antigen. The Fc region is not antigen specific, but is necessary for other antibody functions such as complement fixation and cell lysis.

Abbreviations: Fab, fragment antigen-binding; Fc, fragment crystallizable. 


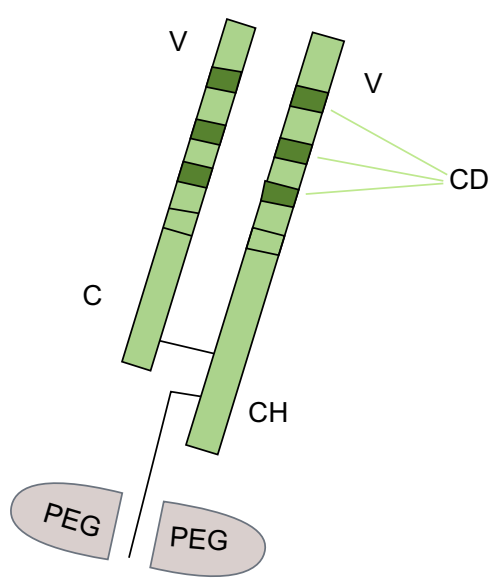

Figure 2 Certolizumab pegol.

Notes: Humanized Fab fragment. Certolizumab pegol is a polyethylene glycosylated Fab fragment of humanized ( $95 \%$ human IgG I isotype) anti-TNF- $\alpha$ monoclonal antibody. Abbreviations: $\mathrm{C}$, constant region; $\mathrm{CD}$, complimentary domain; $\mathrm{CH}$, constant heavy chain region; PEG, polyethylene glycol; TNF, tumor necrosis factor; $\mathrm{V}$, variable region; Fab, fragment antigen-binding.

manner. Its mechanism of action was studied in vitro and compared with that of IFX, ADA, and etanercept, which showed that affinity and neutralizing activity to human soluble TNF was superior to IFX and ADA..$^{34}$ The abilities of CZP to neutralize membrane TNF-mediated signaling are comparable to ADA and IFX, while etanercept may be somewhat less potent. CZP does not induce apoptosis in cultured lymphocytes and monocytes obtained from peripheral blood of healthy donors. ${ }^{35,36}$ Like IFX and ADA (but not etanercept), it inhibits lipopolysaccharide-induced production of IL-1 $\beta .{ }^{34}$ As this nanomolecule does not require glycosylation for function, this drug can be produced in Escherichia coli, a bacterial host. This makes the production of CZP potentially less expensive than the existing anti-TNF- $\alpha$ therapies. ${ }^{37}$

\section{Pharmacological properties}

The pharmacological properties can be summarized as follows: ${ }^{38}$

- inhibits soluble and membrane-bounded TNF in a dosedependent manner;

- inhibits lipopolysaccharide-induced TNF- $\alpha$ and IL-1 $\beta$ production in human monocytes;

- due to the lack of the Fc region, does not induce complement or antibody-dependent cytotoxicity in vitro;

- induces nonapoptotic cell death, probably via signaling transmembrane TNF- $\alpha$;

- probably because of PEGylation, it is distributed into inflamed tissues to a greater extent than IFX and ADA.

CZP has the following pharmacokinetic characteristics:

- Its circulatory half-life is approximately 14 days for all doses administered.
- Pharmacokinetics of the PEG moiety is dependent on renal function, as it is excreted through the kidneys.

- Following subcutaneous administration, peak plasma concentration is reached between 54 and 171 hours, and bioavailability after subcutaneous injection is $80 \%$ compared with the intravenous route.

- Coadministration of CZP and MTX has no significant effect on the pharmacokinetics of the latter.

- MTX-treated patients have lower rates of anti-CZP antibodies; therefore, therapeutic plasma levels of CZP tend to last longer when administered together with MTX.

\section{Clinical efficacy}

In 2009, the European Commission approved CZP for the treatment of active PsA in adults with inadequate response to previous DMARD therapy. In 2013, the US Food and Drug Administration approved CZP for the treatment of adult patients with active PsA. The recommended dose of CZP for adult patients with PsA is $400 \mathrm{mg}$ (given as two subcutaneous injections of $200 \mathrm{mg}$ each) initially and at weeks 2 and 4 , followed by $200 \mathrm{mg}$ every other week or $400 \mathrm{mg}$ every 4 weeks (Q4W) for maintenance dosing. ${ }^{11}$

RAPID-PsA, a 24-week double-blind and placebocontrolled trial of CZP in 409 patients with active PsA, was the pivotal study for CZP approval. ${ }^{27}$ Patients with diagnosis of PsA according to the Classification Criteria for Psoriatic Arthritis with active disease ( $\geq 3$ tender joints, $\geq 3$ swollen joints, erythrocyte sedimentation rate $\geq 28 \mathrm{~mm} / \mathrm{h}$ (Westergren) or C-reactive protein $>7.9 \mathrm{mg} / \mathrm{L}$ ) were recruited. Patients had previously failed $\geq 1$ DMARD. Concomitant and permitted DMARDs were MTX, with doses up to $25 \mathrm{mg} /$ week, sulfasalazine, up to $3 \mathrm{~g} /$ day, and leflunomide, up to $20 \mathrm{mg} /$ day, and were used by $70 \%$ of patients. Almost $20 \%$ of recruited patients had received one previous TNFi. At baseline, $26 \%$ of patients had dactylitis and $64 \%$ had enthesitis. Patients were randomized 1:1:1 to placebo every 2 weeks (Q2W), or $400 \mathrm{mg}$ CZP at weeks 0, 2, and 4, followed by either $200 \mathrm{mg}$ CZP Q2W or $400 \mathrm{mg}$ CZP Q4W.

At week 12 , statistically significant numbers of CZP patients achieved the clinical primary endpoint: American College of Rheumatology 20\% (ACR20) responses (58\% CZP 200 every other week, $52 \%$ CZP 400 Q4W) compared with $24 \%$ of patients receiving placebo $(P<0.001)$. The other primary endpoint was radiographic progression from baseline to week 24 as measured by van der Heijde modified Total Sharp Score (mTSS), which would be discussed in the "Radiographic progression" section.

Secondary endpoints included ACR20/50/70 at week 24, physical function measured by change in Health Assessment 
Questionnaire-Disability Index (HAQ-DI), and 75\% and 90\% reduction in the Psoriasis Area and Severity Index (PASI 75/90). ${ }^{27,39}$ At week 24, mean change from baseline in Health Assessment Questionnaire was - 0.50 (CZP combined arms) versus -0.19 (placebo).

At week 24, statistically significant higher number of patients in CZP group achieved PASI 75 response $(62 \%$ of patients receiving CZP $200 \mathrm{mg}$ Q2W and 60\% of patients receiving CZP $400 \mathrm{mg}$ Q4W) compared with $15 \%$ of patients receiving placebo. ${ }^{27}$ In addition, PASI 90 response rates were higher in CZP groups compared with placebo through week 24. At these points, MDA was achieved in 33\% of patients receiving CZP $200 \mathrm{mg}$ Q2W and 34\% of patients receiving CZP $400 \mathrm{mg}$ Q4W, compared with 6\% of patients in the placebo group. ${ }^{27}$ ACR20/50/70 responses, MDA, HAQ-DI, pain (visual analog scale), and PASI 75 remained stable from week 24 to 48 in the CZP groups (Table 1). ${ }^{40}$

In patients with or without previous TNFi treatment, ACR response rates were higher in patients in CZP arms. ${ }^{40}$

MTX was the most common concomitant DMARD, with similar use across treatment groups. ${ }^{27}$ Concomitant DMARD use did not appear to affect response to CZP as there were similar ACR20 (56.8 vs 50.0) and PsA response criteria (68.3 vs 73.0) responses at week 12 for patients with and without concomitant DMARD use, respectively. ${ }^{27}$

Improvements in joints involvement, skin, enthesitis, dactylitis, and nail disease were seen as soon as only 1 week and maintained over time. ${ }^{27}$

\section{Patient-reported outcomes}

In 2014, Gladman et $\mathrm{al}^{39}$ published the impact of CZP on patient-reported outcomes (PROs) in patients with PsA with or without previous exposure to the use of TNFi from the RAPID-PsA trial. ${ }^{27}$ The PROs assessed were HAQ-DI, health status (measured by the Short Form-36 health survey), Psoriatic Arthritis Quality of Life, Fatigue Assessment Scale, patient assessment of pain (visual analog scale), and Dermatology Life Quality Index. At baseline, all patients had a significant impairment in functionality and quality of life. CZP led to rapid and significant improvement in all PROs at week 24, irrespective of previous TNFi exposure. In contrast with other TNFi studies, in this trial, PROs had poor correlation with clinical outcomes.

\section{Productivity}

PsA has a great impact on the state of employment and labor productivity, both outside and within the home. A high proportion of patients with PsA suffer severe disability and loss of work productivity, and many of them are forced to early retirements due to inability to perform work activities. ${ }^{41,42}$ Kavanaugh et $\mathrm{al}^{43}$ evaluated, in the RAPID-PsA study, the effect of CZP on productivity outside and within the home. The authors used the Work Productivity Survey, which is an innovative validated questionnaire assessing the impact of arthritis on patient productivity in the workplace and at home, and on participation in family, social, and leisure activities. CZP led to quick and significant improvements in the workplace and household productivity. This was accomplished as soon as 4 weeks and continued through week 24. CZP treatment allowed reducing absenteeism and presenteeism for employed patients in both active drug treatment groups, compared with placebo, and also improved productivity within the home, with fewer days of lost participation in family, social, and leisure activities per month.

\section{Radiographic progression}

Radiographic progression was one of the primary endpoints in the RAPID PsA study, and was measured as a change from baseline to week 24, of the van der Heijde mTSS. ${ }^{44}$ The mTSS nonprogression rate was higher in CZP than in placebo group in all analyses. ${ }^{44}$ This effect was maintained in CZP groups up to week $48 .^{44}$

Multiple post hoc analyses demonstrated that CZP inhibited radiographic progression compared with placebo, particularly in patients with high baseline mTSS and C-reactive protein levels. $^{44}$

\section{Axial involvement}

Treatment recommendations for axial disease are derived from diagnostic criteria, screening, monitoring, and response to therapy in ankylosing spondylitis since these data are not available for axial PsA. ${ }^{23}$ The RAPID trial did not assess axial involvement in PsA. ${ }^{27}$ In the RAPID-axSpA trial, CZP rapidly reduced the signs and symptoms of axial Spondyloarthritis (axSpA). ${ }^{45}$ In that trial, patients with PsA and axial involvement were not excluded, but were not reported separately. Experts in PsA agree from own experience that efficacy of TNFi on axial involvement in PsA is similar to that in axSpA. ${ }^{23,46}$

\section{Safety}

CZP showed a good safety profile in randomized clinical trials in patients with RA.

In patients with PsA, nasopharyngitis $(8.7 \%$ in $\mathrm{CZP}$ group vs $7.4 \%$ in placebo) and upper respiratory tract infections (7.8\% in CZP group vs $5.1 \%$ in placebo) were the most common adverse events in CZP combined group through week $24 .{ }^{27}$ The most common noninfectious adverse 
Table I Efficacy of CZP in patients with psoriatic arthritis (RAPID-PsA trial)

\begin{tabular}{|c|c|c|c|c|c|c|}
\hline \multirow[t]{3}{*}{ Outcome } & \multicolumn{2}{|c|}{$\begin{array}{l}\text { CZP } 200 \text { Q2W } \\
n=138(\%)\end{array}$} & \multicolumn{2}{|c|}{$\begin{array}{l}\text { CZP } 400 \text { Q4W } \\
\mathrm{n}=135(\%)\end{array}$} & \multicolumn{2}{|l|}{$\begin{array}{l}\text { Placebo } \\
n=136(\%)\end{array}$} \\
\hline & \multicolumn{6}{|l|}{ Week } \\
\hline & 12 & 24 & 12 & 24 & 12 & 24 \\
\hline ACR20 (\%) & 58 & 63.8 & 52 & 56.3 & 24 & 23.5 \\
\hline ACR50 (\%) & 36 & 44.2 & 32.6 & 40 & 11 & 12.5 \\
\hline ACR70 (\%) & 24.6 & 28.3 & 12.6 & 23.7 & 2.9 & 4.4 \\
\hline PASI 50 (\%) & 68.9 & $\mathrm{n} / \mathrm{a}$ & 63.2 & $\mathrm{n} / \mathrm{a}$ & 26.7 & $\mathrm{n} / \mathrm{a}$ \\
\hline PASI 75 (\%) & 46.7 & 62.2 & 47.4 & 60.5 & 14 & 15.1 \\
\hline PASI 90 (\%) & 22.2 & $\mathrm{n} / \mathrm{a}$ & 19.7 & $\mathrm{n} / \mathrm{a}$ & 4.7 & $\mathrm{n} / \mathrm{a}$ \\
\hline PsARC (\%) Concomitant & $73.7(73 / 99)$ & $\mathrm{n} / \mathrm{a}$ & $63.0(63 / 100)$ & $\mathrm{n} / \mathrm{a}$ & $42.0(37 / 88)$ & $\mathrm{n} / \mathrm{a}$ \\
\hline \multicolumn{7}{|l|}{ DMARD at baseline } \\
\hline PsARC (\%) No concomitant & $71.8(28 / 39)$ & $\mathrm{n} / \mathrm{a}$ & $74.3(26 / 35)$ & $\mathrm{n} / \mathrm{a}$ & $31.3(15 / 48)$ & $\mathrm{n} / \mathrm{a}$ \\
\hline \multicolumn{7}{|l|}{ DMARD at baseline } \\
\hline MDA (\%) & $\mathrm{n} / \mathrm{a}$ & 33.3 & $\mathrm{n} / \mathrm{a}$ & 34.1 & $\mathrm{n} / \mathrm{a}$ & 5.9 \\
\hline \multicolumn{7}{|l|}{ from baseline \pm SD) } \\
\hline Leeds Enthesitis Index, n & $\mathrm{n} / \mathrm{a}$ & 91 & $\mathrm{n} / \mathrm{a}$ & 88 & $\mathrm{n} / \mathrm{a}$ & 84 \\
\hline $\begin{array}{l}\text { Mean change from } \\
\text { baseline } \pm \text { SD }\end{array}$ & & $-1.1 \pm 1.8$ & & $-2.0 \pm 1.8^{*}$ & & $-1.8 \pm 1.9 * *$ \\
\hline Leeds Dactylitis Index, n & $\mathrm{n} / \mathrm{a}$ & 35 & $\mathrm{n} / \mathrm{a}$ & 35 & $\mathrm{n} / \mathrm{a}$ & 38 \\
\hline $\begin{array}{l}\text { Mean change from } \\
\text { baseline } \pm S D\end{array}$ & & $-22.0 \pm 46.9$ & & $-40.7 \pm 34.6 * *$ & & $-53.5 \pm 69 . I^{*}$ \\
\hline
\end{tabular}

Notes: $* P<0.001 ; * * P<0.003$. Data from Mease et al. ${ }^{27}$

Abbreviations: ACR, American College of Rheumatology; CZP, certolizumab pegol; DMARD, disease-modifying antirheumatic drug; HAQ-DI, Health Assessment Questionnaire-Disability Index; MDA, minimal disease activity; n/a, not available; PASI, Psoriasis Area and Severity Index; PsARC, psoriatic arthritis response criteria; Q2W, every 2 weeks; Q4W, every 4 weeks; SD, standard deviation.

events were headache (3.6\% in CZP vs $1.5 \%$ in placebo) and diarrhea (3.6\% in CZP vs $2.9 \%$ in placebo). ${ }^{27}$

Increases in liver enzymes were more frequently reported in CZP patients. ${ }^{27}$

Injection site reactions such as erythema, hematoma, itching, pain, and swelling were more frequently observed in CZP groups than in placebo group. ${ }^{27}$

Antibodies to CZP were detectable in approximately $11.7 \%$ of patients at week $24 .{ }^{47}$

Two deaths occurred during the first 24 weeks; one myocardial infarct in the CZP $200 \mathrm{mg}$ Q2W group and one sudden death of unknown cause in the CZP $400 \mathrm{mg}$ Q4W group. Both deaths were considered unrelated to study medication by the investigators. ${ }^{27}$

In patients with PsA, three malignancies (two cases of breast cancer and one case of lymphoma) were reported during the dose-blind and open-label periods, of which two were fatal (lymphoma and one case of breast cancer) ${ }^{47}$ The profile of malignancies with CZP in patients with PsA was generally similar to that seen earlier in patients with RA.

\section{Pregnancy}

CZP cross-placental transfer is different from that of other TNFi. Because it is not actively transported across the placenta, concentrations in the fetus would be expected to be lower, and hence, its use is potentially safer during pregnancy than the other TNFi currently available.

Recently, 31 pregnant women with inflammatory bowel disease receiving IFX $(n=11)$, ADA $(n=10)$, or CZP $(n=10)$ were studied. ${ }^{48}$ Serum concentrations of the drugs were measured at birth in the mother, infant, and in cord blood, and then monthly in the infant until the drugs were undetectable. Drug concentrations in the cord and in the infant at birth were compared with those of the mother. Concentrations of IFX and ADA, but not CZP, were higher in infants at birth and their cords than in their mothers. The levels of CZP in infants and their cords were $<2 \mathrm{~g} / \mathrm{mL}$. The median level of IFX in the cord was $160 \%$ that of the mother, the median level of ADA in the cord was $153 \%$ that of the mother, and the median level of CZP in the cord was $3.9 \%$ that of the mother. IFX and ADA could be detected in the infants for as long as 6 months. No congenital anomalies or serious complications were reported. ${ }^{48}$

In a retrospective analysis of the UCB Pharma global safety database, all medically confirmed cases of pregnancy during clinical trials of CZP and postmarketing reports through March 28, 2013, were included. Of 625 reported pregnancies, 372 (59.5\%) had known outcomes. Paternal exposure pregnancies $(n=33)$ reported 27 live births, four miscarriages, 
one induced abortion, and one stillbirth. Maternal exposure pregnancies $(n=339)$ reported 254 live births, 52 miscarriages, 32 induced abortions, and one stillbirth. Almost all reported pregnancies had exposure to CZP in the first trimester, when organogenesis takes place, and a third of them continued the drug into the second and/or third trimesters. The most frequent indications for maternal CZP use were Crohn's disease (192/339) and rheumatic diseases (118/339). Twelve cases of congenital malformation and a single neonatal death were reported. Out of 253 pregnancies with known outcomes, 191 $(75.5 \%)$ resulted in live births, $37(14.6 \%)$ in spontaneous miscarriages, and $25(9.9 \%)$ women had elective terminations. ${ }^{49}$ Of the 191 live births after maternal CZP exposure, there were three reported cases of congenital disorder. These rates are similar to what is observed in the general population; none of these events were considered related to CZP administration by the treating physicians. ${ }^{50,51}$

\section{CZP loading dose}

The recommendation for treatment of $\mathrm{RA}$ with $\mathrm{CZP}$ includes an initial loading dose (LD) of $400 \mathrm{mg}$ at weeks 0,2 , and 4, followed by a maintenance dose of CZP $200 \mathrm{mg}$ Q2W or 400 mg Q4W. Several other anti-TNFs also employ a boosted dosing regimen during the initial phase of treatment. For example, the IFX dosing schedule for RA treatment specifies short intervals between the first three infusions $(3 \mathrm{mg} / \mathrm{kg}$ at 0,2 , and 6 weeks), followed by a dosing interval of every 8 weeks during the maintenance phase. ${ }^{52}$ In addition, ADA requires an initial LD in several diseases including Crohn's disease, ulcerative colitis, and plaque Ps. ${ }^{53}$ The rationale for an LD is that it produces higher drug concentrations during early treatment time points, accelerates response to the drug, and reduces the production of anti-monoclonal drug antibodies. Takeuchi et $\mathrm{al}^{54}$ published a post hoc analysis of two Japanese clinical studies comparing the efficacy and safety of CZP with and without LD in RA patients. Patients randomized to CZP 200 mg Q2W groups starting with LD (400 mg weeks 0/2/4) (in the J-RAPID ${ }^{55}$ trial: $n=82$, and in the HIKARI ${ }^{56}$ trial: $n=116$ ) and patients randomized to placebo groups who subsequently started CZP Q2W without LD in the Open Level Extension study (no-LD group; J-RAPID: n=61, HIKARI: n=99) were analyzed. ${ }^{54}$ In both trials, the LD groups showed more rapid initial ACR20/50/70 kinetics, maintained higher ACR50/70 responses until 24 weeks, and developed anti-CZP antibodies less frequently (J-RAPID: 1.2\% vs 4.9\%; HIKARI: $17.2 \%$ vs $27.3 \%$ ) compared to the no-LD groups. Similar safety profiles were reported between LD and no-LD groups. ${ }^{54}$ This analysis, even with its limitations, provides data to support what was expected based in theory considerations.

\section{Place in therapy}

TNFi are placed in all international and local guidelines after traditional DMARDs failure, ${ }^{21}$ and would remain in that place in the European League Against Rheumatism and Group for Research and Assessment of Psoriasis and Psoriatic Arthritis new recommendations that are going to be published soon. In that sense, CZP should be placed as another TNFi option. The evidence of efficacy in all domains including dactylitis and enthesitis might incline rheumatologists to choose this TNFi in patients in whom these conditions predominate. Also, the fact that CZP has evidence from randomized controlled trial for its efficacy in TNFi failures favors its use in that population. Because of the low cross-placental transfer and no detectable transfer in breast milk, CZP may be considered the TNFi of choice in pregnant patients and in the female patient considering pregnancy; however, the ultimate decision needs to be based on the clinical picture and patient preference. The risks and benefits of therapy should be individualized balancing the neonatal risks against the risk of disease flare or the course of a pregnancy with a very active disease, which might have far more consequences to neonatal development. In any case, if a pregnant patient is doing well on other TNFi, there is no indication, and even a potential risk, of switching to CZP.

\section{Conclusion}

CZP, the newest original TNFi, has shown similar efficacy when compared with the existing TNF blockers in several manifestations of Ps disease.

In a market with many options for TNF blockage, is this new TNFi offering anything different? CZP has some features that might make it an attractive option: a long halflife that allows a fortnightly or monthly subcutaneous drug regime; the lack of complement fixation with potentially less immunosuppressive effect and less cross-placental transfer; pegylation that improves distribution into inflamed tissues; and evidence that with a loading dose, quick and long-lasting efficacy could be obtained, reducing the generation of antiTNFi (anti-ADA) antibodies.

Its safety profile looks similar to other TNFi up to now, although more data from registries are needed.

In summary, CZP is a promising TNFi with a novel composition, which is already performing according to the expectations. 
Until not long ago, therapeutic options for patients with PsA were limited and of little efficacy. New options are very much welcomed by rheumatologists and patients alike.

\section{Disclosure}

ERS has received grants and/or speaking fees from and/or provided expert advice to UCB Pharma, AbbVie, Pfizer, BMS, Novartis, and Roche. JR has received speaking fees from AbbVie and Pfizer. The authors report no other conflicts of interest in this work.

\section{References}

1. Alamanos Y, Voulgari PV, Drosos AA. Incidence and prevalence of psoriatic arthritis: a systematic review. J Rheumatol. 2008;35(7): 1354-1358.

2. Soriano ER, Rosa J, Velozo E, et al. Incidence and prevalence of psoriatic arthritis in Buenos Aires, Argentina: a 6-year health management organization-based study. Rheumatology (Oxford). 2011;50(4): 729-734.

3. Gladman DD, Antoni C, Mease P, Clegg DO, Nash P. Psoriatic arthritis: epidemiology, clinical features, course, and outcome. Ann Rheum Dis. 2005;64 Suppl 2:ii14-ii17.

4. Torre Alonso JC, Rodriguez Perez A, Arribas Castrillo JM, Ballina Garcia J, Riestra Noriega JL, Lopez Larrea C. Psoriatic arthritis (PA): a clinical, immunological and radiological study of 180 patients. Br J Rheumatol. 1991;30(4):245-250.

5. Gladman DD, Shuckett R, Russell ML, Thorne JC, Schachter RK. Psoriatic arthritis (PSA) - an analysis of 220 patients. $Q J$ Med 1987;62(238):127-141.

6. Ory PA, Gladman DD, Mease PJ. Psoriatic arthritis and imaging. Ann Rheum Dis. 2005;64 Suppl 2:ii55-ii57.

7. Siannis F, Farewell VT, Cook RJ, Schentag CT, Gladman DD. Clinical and radiological damage in psoriatic arthritis. Ann Rheum Dis. 2006;65(4):478-481.

8. Rosen CF, Mussani F, Chandran V,Eder L, ThavaneswaranA, Gladman DD. Patients with psoriatic arthritis have worse quality of life than those with psoriasis alone. Rheumatology (Oxford). 2012;51(3):571-576.

9. Husted JA, Gladman DD, Farewell VT, Long JA, Cook RJ. Validating the SF-36 health survey questionnaire in patients with psoriatic arthritis. J Rheumatol. 1997;24(3):511-517.

10. Husted JA, Gladman DD, Farewell VT, Cook RJ. Health-related quality of life of patients with psoriatic arthritis: a comparison with patients with rheumatoid arthritis. Arthritis Rheum. 2001;45(2): $151-158$.

11. Hansen RB, Kavanaugh A. Certolizumab pegol for the treatment of psoriatic arthritis. Expert Rev Clin Immunol. 2015;11(3):307-318.

12. Gossec L, Smolen JS, Gaujoux-Viala C, et al. European League against rheumatism recommendations for the management of psoriatic arthritis with pharmacological therapies. Ann Rheum Dis. 2012;71(1):4-12.

13. Costa L, Caso F, Ramonda R, et al. Metabolic syndrome and its relationship with the achievement of minimal disease activity state in psoriatic arthritis patients: an observational study. Immunol Res. 2015;61(1-2):147-153.

14. Eder L, Thavaneswaran A, Chandran V, Cook RJ, Gladman DD. Obesity is associated with a lower probability of achieving sustained minimal disease activity state among patients with psoriatic arthritis. Ann Rheum Dis. 2015;74(5):813-817.

15. Costa L, Caso F, Atteno M, et al. Impact of 24-month treatment with etanercept, adalimumab, or methotrexate on metabolic syndrome components in a cohort of 210 psoriatic arthritis patients. Clin Rheumatol. 2014;33(6):833-839.
16. Soriano ER, Acosta-Felquer ML, Luong P, Caplan L. Pharmacologic treatment of psoriatic arthritis and axial spondyloarthritis with traditional biologic and non-biologic DMARDs. Best Practice Res Clin Rheumatol. 2014;28(5):793-806.

17. Gladman DD. Early psoriatic arthritis. Rheum Dis Clin North Am. 2012;38(2):373-386.

18. Acosta Felquer ML, Ferreyra Garrott L, Marin J, et al. Remission criteria and activity indices in psoriatic arthritis. Clin Rheumatol. 2014;33(9):1323-1330.

19. Gladman DD, Mease PJ, Strand V, et al. Consensus on a core set of domains for psoriatic arthritis. J Rheumatol. 2007;34(5):1167-1170.

20. Schoels MM, Braun J, Dougados M, et al. Treating axial and peripheral spondyloarthritis, including psoriatic arthritis, to target: results of a systematic literature search to support an international treatto-target recommendation in spondyloarthritis. Ann Rheum Dis. 2014;73(1):238-242.

21. Soriano ER. Treatment guidelines for psoriatic arthritis. Int $J$ Clin Rheumatol. 2009;4:329-342.

22. Caso F, Costa L, Del Puente A, et al. Pharmacological treatment of spondyloarthritis: exploring the effectiveness of nonsteroidal antiinflammatory drugs, traditional disease-modifying antirheumatic drugs and biological therapies. Ther Adv Chronic Dis. 2015;6(6):328-338.

23. Coates LC, Kavanaugh A, Mease PJ, et al. Group for research and assessment of psoriasis and psoriatic arthritis: Treatment recommendations for psoriatic arthritis 2015. Arthritis Rheumatol. Epub 2016 Jan 8.

24. Soriano ER. The actual role of therapy with traditional diseasemodifying antirheumatic drugs in psoriatic arthritis. J Rheumatol Suppl. 2012;89:67-70

25. Mease PJ, Goffe BS, Metz J, VanderStoep A, Finck B, Burge DJ. Etanercept in the treatment of psoriatic arthritis and psoriasis: a randomised trial. Lancet. 2000;356(9227):385-390.

26. Mease PJ, Gladman DD, Ritchlin CT, et al. Adalimumab for the treatment of patients with moderately to severely active psoriatic arthritis: results of a double-blind, randomized, placebo-controlled trial. Arthritis Rheum. 2005;52(10):3279-3289.

27. Mease PJ, Fleischmann R, Deodhar AA, et al. Effect of certolizumab pegol on signs and symptoms in patients with psoriatic arthritis: 24-week results of a Phase 3 double-blind randomised placebo-controlled study (RAPID-PsA). Ann Rheum Dis. 2014;73(1):48-55.

28. Antoni CE, Kavanaugh A, van der Heijde D, et al. Two-year efficacy and safety of infliximab treatment in patients with active psoriatic arthritis: findings of the Infliximab Multinational Psoriatic Arthritis Controlled Trial (IMPACT). J Rheumatol. 2008;35(5):869-876.

29. Kavanaugh A, McInnes I, Mease P, et al. Golimumab, a new human tumor necrosis factor alpha antibody, administered every four weeks as a subcutaneous injection in psoriatic arthritis: Twenty-four-week efficacy and safety results of a randomized, placebo-controlled study. Arthritis Rheum. 2009;60(4):976-986.

30. Delgado Frias E, Diaz Gonzalez JF. [Certolizumab pegol]. Rheumatol Clin. 2011;6S3:S7-S11. Spanish.

31. Chimenti MS, Saraceno R, Chiricozzi A, Giunta A, Chimenti S, Perricone R. Profile of certolizumab and its potential in the treatment of psoriatic arthritis. Drug Des Devel Ther. 2013;7:339-348.

32. Felquer ML, Soriano ER. New treatment paradigms in psoriatic arthritis: an update on new therapeutics approved by the U.S. Food and Drug Administration. Curr Opinion Rheumatol. 2015;27(2):99-106.

33. Caso F, Lubrano E, Del Puente A, et al. Progress in understanding and utilizing TNF-alpha inhibition for the treatment of psoriatic arthritis. Expert Rev Clin Immunol. 2015:1-17.

34. Nesbitt A, Fossati G, Bergin M, et al. Mechanism of action of certolizumab pegol (CDP870): in vitro comparison with other anti-tumor necrosis factor alpha agents. Inflamm Bowel Dis. 2007;13(11):1323-1332.

35. Lugering A, Schmidt M, Lugering N, Pauels HG, Domschke W, Kucharzik T. Infliximab induces apoptosis in monocytes from patients with chronic active Crohn's disease by using a caspase-dependent pathway. Gastroenterology. 2001;121(5):1145-1157. 
36. Shen C, Assche GV, Colpaert S, et al. Adalimumab induces apoptosis of human monocytes: a comparative study with infliximab and etanercept. Aliment Pharmacol Ther. 2005;21(3):251-258.

37. Rosa J, Sabelli M, Soriano ER. Prefilled certolizumab pegol $($ Cimzia $((\circledR)))$ syringes for self-use in the treatment of rheumatoid arthritis. Med Devices (Auckl). 2010;3:25-31.

38. Dhillon S. Certolizumab pegol: a review of its use in patients with axial spondyloarthritis or psoriatic arthritis. Drugs. 2014;74(9):999-1016.

39. Gladman D, Fleischmann R, Coteur G, Woltering F, Mease PJ. Effect of certolizumab pegol on multiple facets of psoriatic arthritis as reported by patients: 24-week patient-reported outcome results of a phase III, multicenter study. Arthritis Care Res (Hoboken). 2014;66(7):1085-1092.

40. Mease P, Fleischmann R, Wollenhaupt J, et al. Effect of certolizumab pegol over 48 weeks on signs and symptoms in patients with psoriatic arthritis with and without prior tumor necrosis factor inhibitor exposure. Arthritis Rheum. 2013;65 (Suppl):S132.

41. Tillett W, de-Vries C, McHugh NJ. Work disability in psoriatic arthritis: a systematic review. Rheumatology (Oxford). 2012;51(2):275-283.

42. Mease PJ, Menter MA. Quality-of-life issues in psoriasis and psoriatic arthritis: outcome measures and therapies from a dermatological perspective. J Am Acad Dermatol. 2006;54(4):685-704.

43. Kavanaugh A, Gladman D, van der Heijde D, Purcaru O, Mease P. Improvements in productivity at paid work and within the household, and increased participation in daily activities after 24 weeks of certolizumab pegol treatment of patients with psoriatic arthritis: results of a phase 3 double-blind randomised placebo-controlled study. Ann Rheum Dis. 2015;74(1):44-51.

44. van der Heijde D, Fleischmann R, Wollenhaupt J, et al. Effect of different imputation approaches on the evaluation of radiographic progression in patients with psoriatic arthritis: results of the RAPID-PsA 24-week phase III double-blind randomised placebo-controlled study of certolizumab pegol. Ann Rheum Dis. 2014;73(1):233-237.

45. Landewé R, Braun J, Deodhar A, et al. Efficacy of certolizumab pegol on signs and symptoms of axial spondyloarthritis including ankylosing spondylitis: 24-week results of a double-blind randomised placebocontrolled Phase 3 study. Ann Rheum Dis. 2014;73(1):39-47.

46. Nash P, Lubrano E, Cauli A, Taylor WJ, Olivieri I, Gladman DD. Updated guidelines for the management of axial disease in psoriatic arthritis. J Rheumatol. 2014;41(11):2286-2289.
47. European Medicines Agency. Annex 1: summary of product characteristics (Cimzia). Available from: www.ema.europa. eu/docs/en_GB/ document library/EPAR _ Product_Information/human/001037/ WC500069763.pdf www.ema.europa. eu/docs/en_GB/document_ library/EPAR_-_Product_Information/human/001037/WC500069763. pdf. Accessed October 18, 2014.

48. Mahadevan U, Wolf DC, Dubinsky M, et al. Placental transfer of antitumor necrosis factor agents in pregnant patients with inflammatory bowel disease. Clin Gastroenterol Hepatol. 2013;11(3):286-292; quiz e224.

49. Clowse ME, Wolf DC, Forger F, et al. Pregnancy outcomes in subjects exposed to certolizumab pegol. J Rheumatol. 2015;42(12): 2270-2278.

50. Wakefield I, Stephens S, Foulkes R, Nesbitt A, Bourne T. The use of surrogate antibodies to evaluate the developmental and reproductive toxicity potential of an anti-TNFalpha PEGylated Fab' monoclonal antibody. Toxicol Sci. 2011;122(1):170-176.

51. Marchioni RM, Lichtenstein GR. Tumor necrosis factor-alpha inhibitor therapy and fetal risk: a systematic literature review. World J Gastroenterol. 2013;19(17):2591-2602.

52. Remicade (infliximab) prescribing information; 2013. Available from: http://www.remicade.com/shared/product/remicade/prescribinginformation.pdf. Accessed March 10, 2016.

53. Humira (adalimumab) prescribing information; 2014. Available from: http://www.rxabbvie.com/pdf/humira.pdf. Accessed March 10, 2016.

54. Takeuchi T, Yamamoto K, Yamanaka H, et al. Post-hoc analysis showing better clinical response with the loading dose of Certolizumab pegol in Japanese patients with active rheumatoid arthritis. Mod Rheumatol. 2015:1-26.

55. Yamamoto K, Takeuchi T, Yamanaka H, et al. Efficacy and safety of certolizumab pegol plus methotrexate in Japanese rheumatoid arthritis patients with an inadequate response to methotrexate: the J-RAPID randomized, placebo-controlled trial. Mod Rheumatol. 2014;24(5):715-724.

56. Yamamoto K, Takeuchi T, Yamanaka H, et al. Efficacy and safety of certolizumab pegol without methotrexate co-administration in Japanese patients with active rheumatoid arthritis: the HIKARI randomized, placebo-controlled trial. Mod Rheumatol. 2014;24(4):552-560.
Open Access Rheumatology Research and Reviews

\section{Publish your work in this journal}

Open Access Rheumatology Research and Reviews is an international, peer-reviewed, open access journal, publishing all aspects of clinical and experimental rheumatology in the clinic and laboratory including the following topics: Pathology, pathophysiology of rheumatological diseases; Investigation, treatment and management of rheumatological

\section{Dovepress}

diseases; Clinical trials and novel pharmacological approaches for the treatment of rheumatological disorders. The manuscript management system is completely online and includes a very quick and fair peerreview system, which is all easy to use. Visit http://www.dovepress.com/ testimonials.php to read real quotes from published authors. 